\title{
Anopheles culicifacies breeding in brackish waters in Sri Lanka and implications for malaria control
}

\author{
Pavilupillai J Jude1, Sangaralingam Dharshini², Muthuladchumy Vinobaba², Sinnathamby N Surendran*1 and \\ Ranjan Ramasamy ${ }^{3}$
}

\begin{abstract}
Background: Anopheles culicifacies is the major vector of both falciparum and vivax malaria in Sri Lanka, while Anopheles subpictus and certain other species function as secondary vectors. In Sri Lanka, An. culicifacies is present as a species complex consisting of species B and E, while An. subpictus exists as a complex of species A-D. The freshwater breeding habit of An. culicifacies is well established. In order to further characterize the breeding sites of the major malaria vectors in Sri Lanka, a limited larval survey was carried out at a site in the Eastern province that was affected by the 2004 Asian tsunami.

Methods: Anopheline larvae were collected fortnightly for six months from a brackish water body near Batticaloa town using dippers. Collected larvae were reared in the laboratory and the emerged adults were identified using standard keys. Sibling species status was established based on Y-chromosome morphology for An. culicifacies larvae and morphometric characteristics for An. subpictus larvae and adults. Salinity, dissolved oxygen and pH were determined at the larval collection site.

Results: During a six month study covering dry and wet seasons, a total of 935 anopheline larvae were collected from this site that had salinity levels up to 4 parts per thousand at different times. Among the emerged adult mosquitoes, 661 were identified as An. culicifacies s.l. and 58 as An. subpictus s.l. Metaphase karyotyping of male larvae showed the presence of species $E$ of the Culicifacies complex, and adult morphometric analysis the presence of species B of the Subpictus complex. Both species were able to breed in water with salinity levels up to $4 \mathrm{ppt}$.

Conclusions: The study demonstrates the ability of An. culicifacies species $\mathrm{E}$, the major vector of falciparum and vivax malaria in Sri Lanka, to oviposit and breed in brackish water. The sibling species B in the An. subpictus complex, a wellknown salt water breeder and a secondary malaria vector in the country, was also detected at the same site. Since global warming and the rise in sea levels will further increase of inland brackish water bodies, the findings have significant implications for the control of malaria in Sri Lanka and elsewhere.
\end{abstract}

\section{Background}

Anopheles culicifacies sensu lato (s.l.) is well established as the major vector of both falciparum and vivax malaria in Sri Lanka, while Anopheles subpictus s.l. and certain other species function as secondary vectors [1-4]. Both vector species exist as a species complex in Sri Lanka and elsewhere in Asia [reviewed in [1]]. Only species B and E in the An. culicifacies complex of A-E have been detected in Sri Lanka with species $\mathrm{E}$ being incriminated as the major vector of falciparum and vivax malaria $[5,6]$. An. culicifa-

* Correspondence: noble@jfn.ac.lk

${ }^{1}$ Department of Zoology, Faculty of Science, University of Jaffna, Jaffna, Sri Lanka

Full list of author information is available at the end of the article cies species B and E of Sri Lanka can only be differentiated through Y-chromosome morphology [7]. All four known sibling species (A-D) of the An. subpictus complex are present in Sri Lanka [1]. However, only species B of An. subpictus has so far been shown to be a malaria vector in India [8]. The spraying of residual insecticides in households, larviciding breeding sites, the use of insecticide-treated and untreated bed nets, and early case detection and drug treatment are the major measures undertaken by the Ministry of Health to control malaria in the country. These measures have markedly reduced the incidence of malaria in Sri Lanka over the past decade (Figure 1) [9]. The Batticaloa district in the Eastern prov- 


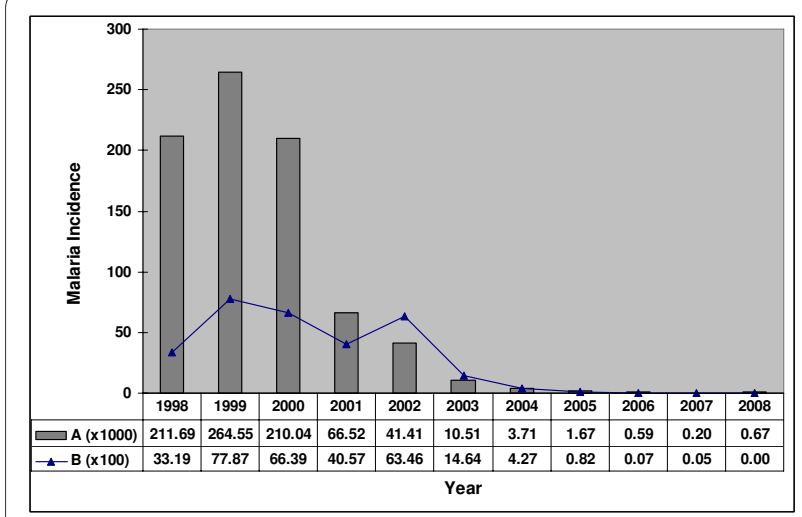

Figure 1 Malaria incidence in the period 1998-2008 due to all species of malaria parasites (A) in Sri Lanka and (B) in Batticaloa district (adapted from data of Deputy Provincial Director for Health, Batticaloa).

ince of Sri Lanka, is located in the country's dry zone. Although it has traditionally been an area endemic for malaria, the Batticaloa district shows a decreasing malaria incidence in keeping with a country-wide trend (Figure 1). The Batticaloa district was badly affected by the Asian tsunami of December 2004. Batticaloa and other tsunami-affected eastern districts (Trincomalee and Ampara) of Sri Lanka had a high incidence of malaria before the tsunami [10], but the decrease in malaria incidence beginning 2004 showed that the tsunami did not increase malaria transmission in Batticaloa (Table 1) or elsewhere in the country (Figure 1).

The city of Batticaloa is surrounded by a lagoon contiguous with the Indian Ocean. The city is connected to the mainland via the Kallady Bridge. This article reports the brackish water breeding ability of species $\mathrm{E}$ of the Culicifacies complex and species B of the Subpictus complex, in the vicinity of Kallady Bridge and discusses the implications of the findings for the control of malaria.

\section{Methods}

Anopheline larvae were collected at a site $25 \mathrm{~m}$ away from the Kallady Bridge (Figure 2) within the city of Batticaloa ( $7^{\circ} 43^{\prime} 07.16^{\prime \prime} \mathrm{N} ; 81^{\circ} 42^{\prime} 31.28^{\prime \prime}$ E). The stagnant and permanent brackish water body where the collection was performed is connected to the large Batticaloa lagoon by a shallow channel. Mangroves and grass line the water body and the lagoon. Larval collections were carried out along the margin of the water body using an $8 \mathrm{~cm}$ diameter and $240 \mathrm{ml}$ capacity dipper. In a single collection five dipper samples were taken from a one $\mathrm{m}^{2}$ area and a total of ten collections were done covering the entire pool in every visit. Samples were collected fortnightly in the period from September 2009 to February 2010. The collected larvae along with water samples were transferred to the Eastern University Zoology laboratory in Batticaloa. The larvae were maintained under laboratory conditions $\left(28 \pm 2^{\circ} \mathrm{C}\right)$ to emerge as adults. Salinity (Salino meter, Atago, Japan), pH (Hanna Instruments, HI 98128, Romania) and dissolved oxygen (Hanna Instruments, HI 8043, Rumania) were measured in the water samples. The larvae and emerged adults were identified at the species level using standard published keys [11-13]. Morphometric characteristics were used to identify sibling species of An. subpictus [14]. Late third and early fourth male larvae from collected An. culicifacies were used to determine Ychromosome morphology, and thereby identify An. culicifacies sibling species as described previously [5]

Table 1: Malaria incidence in the district of Batticaloa in the Eastern province of Sri Lanka for the period 2001-2008 (source: Office of the Deputy Provincial Director of Health, Batticaloa).

\begin{tabular}{|c|c|c|c|c|c|}
\hline \multirow[t]{2}{*}{ Year } & \multirow{2}{*}{$\begin{array}{l}\text { Number of blood } \\
\text { film examined }\end{array}$} & \multicolumn{2}{|c|}{ Number of confirmed cases } & \multirow[t]{2}{*}{ §SPR } & \multirow[t]{2}{*}{ †API } \\
\hline & & P. vivax & P. falciparum & & \\
\hline 2001 & 52,149 & 3,771 & 286 & 7.8 & 7.98 \\
\hline 2002 & 104,279 & 5,864 & 482 & 6.1 & 10.5 \\
\hline 2003 & 109,787 & 1,348 & 116 & 1.3 & 2.5 \\
\hline 2004 & 103,484 & 327 & 94 & 0.4 & 0.7 \\
\hline 2005 & 92,817 & 73 & 09 & 0.08 & 0.14 \\
\hline 2006 & 112,323 & 07 & 00 & $<0.01$ & 0.06 \\
\hline 2007 & 70,414 & 05 & 00 & $<0.01$ & 0.08 \\
\hline 2008 & 59,189 & 00 & 00 & 00 & 00 \\
\hline
\end{tabular}

$\$ S P R$ - slide positivity rate

${ }^{\dagger} \mathrm{API}$ - annual parasite index 


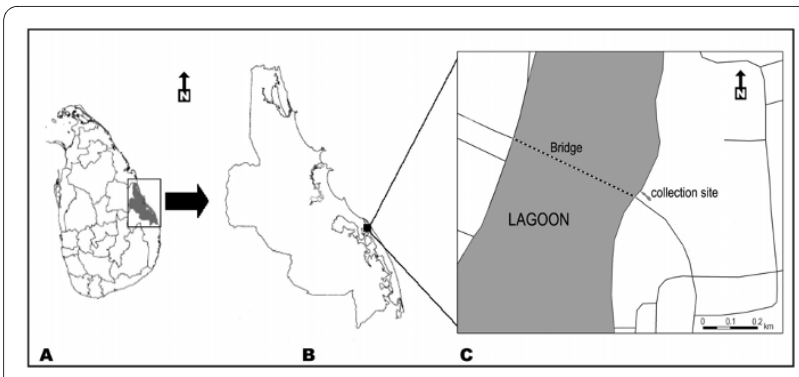

Figure 2 Map showing the larval collection site in the Batticaloa district of Sri Lanka. A - Sri Lanka; B - Batticaloa district; C- Batticaloa lagoon and sampled location.

\section{Results}

A total of 935 anopheline larvae were collected during the six month period. Among the emerged adults 661 were identified as An. culicifacies and 58 as An. subpictus. All the An. subpictus females were identified as sibling species B. Among fifteen randomly selected male An. culicifacies larvae, all five that could be successfully karyotyped possessed a submetacentirc Y-chromosome characteristic of sibling species E. The average measured values of salinity, $\mathrm{pH}$ and dissolved oxygen at larval collection site over the study period are shown in Table 2.

Anopheles culicifacies larvae were also collected from freshwater bodies within one $\mathrm{km}$ proximity to the Kalladay locality and brackish water bodies (salinity ranging from 2-3 parts per thousand) in at a different site called Raalkuli (nearly $110 \mathrm{~km}$ away from the present study location) in the tsunami-affected Trincomalee district of the Eastern province of Sri Lanka in the period from December 2009 to February 2010 (data not shown).

\section{Discussion}

Anopheles culicifacies s.l., the major vector of malaria in the Indian subcontinent, is generally regarded to be intolerant of salinity $[15,16]$, preferring to breed in newly-dug freshwater pits [15], domestic wells and pits used for plantation of coconuts and casurina [16] in India. How- ever An. culicifacies larvae have reportedly been collected from concrete reservoir tanks containing brackish water containing $16-39 \%$ sea water in Oman, even though they survived best in freshwater [17]. Previous studies in Sri Lanka have reported that An. culicifacies s.l. breeds only in freshwater bodies (salinity $<0.5 \mathrm{ppt}$ ) with high dissolved oxygen and is, therefore, confined to the riverine system of the country [18-20]. Vector control strategies through water management in the country are also based on the assumption that An. culicifacies only breeds in freshwater [21]. The brackish water breeding ability of sibling species B of Subpictus complex is, however, well established in India [22] and Sri Lanka [23].

Recent investigation on larval breeding sites of the members of Culicifacies complex in the country suggests that species $E$ can exploit a wide range of fresh water breeding habitats $[1,24]$. However, the findings reported here are the first, from Sri Lanka, that demonstrate the ability of An. culicifacies species E, like species B of the $A n$. subpictus complex, to breed in brackish waters. Anopheles culicifacies species is able to tolerate salinity changes in the same breeding ground over the period of time caused by monsoonal rain that began in late November 2009 and ended in January 2010. Possessing the ability to breed in brackish and fresh waters is a characteristic of An. culicifacies species E that is significant in the context of its traditional major role in malaria transmission in Sri Lanka.

Some members of the different anopheline species complexes show high salinity tolerance and this is associated with malaria transmission in coastal areas in different parts of the world. Anopheles melas and Anopheles merus within the An. gambiae complex are reported to be salt water species [25]. In the Farauti complex, Anopheles farauti No.1 is reported to be saline tolerant [26]. The Anopheles sundaicus complex in Asia, is composed of sibling species that breed in both fresh and saline waters [27].

Table 2: Monthly anopheline collections and measured chemical parameters at Kallady.

\begin{tabular}{|c|c|c|c|c|c|}
\hline \multirow[t]{2}{*}{ Month } & \multicolumn{3}{|c|}{ Chemical parameters } & \multicolumn{2}{|c|}{ Number of adults identified } \\
\hline & pH & $\begin{array}{c}\text { Dissolved } \\
\text { oxygen (mg/L) }\end{array}$ & Salinity (ppt) & An. culicifacies & An. subpictus \\
\hline Sept, 2009 & 8.0 & 1.1 & 4 & 24 & - \\
\hline Oct, 2009 & 7.9 & 1.2 & 4 & 39 & 44 \\
\hline Nov, 2009 & 8.1 & 1.2 & 3 & 56 & 09 \\
\hline Dec, 2009 & 7.9 & 1.4 & 1 & 26 & - \\
\hline Jan, 2010 & 8.2 & 1.4 & 0 & 324 & - \\
\hline Feb, 2010 & 8.3 & 1.5 & 2 & 192 & - \\
\hline
\end{tabular}


It was postulated that salt water breeding species of $A n$. sundaicus s.l. in south-east Asia may increase in numbers and contribute to greater malaria transmission in the wake of the Asian tsunami that produced significant intrusion of sea water into inland areas [28,29]. A larval survey carried out after the tsunami in south India revealed the invasion of An. culicifacies into the affected areas breeding in ground pools and coconut garden pits with salinity ranging from 2.3 to $7.1 \mathrm{ppt}$ [30]. However, it was previously suggested that the tsunami-induced malaria risk was minimal in affected areas of Sri Lanka, since the major malaria vector An. culicifacies s.l. breeds only in freshwater bodies and An. sundaicus s.l. was absent in the country [31]. Although An. culicifacies species $\mathrm{E}$ and $A n$. subpictus species B larvae are now reported from brackish water bodies in the tsunami affected areas, it is clear that this has not increased malaria transmission in the Eastern province to date. This is may be due to the continued implementation of effective malaria control measures in the country.

Whether An. culicifacies began breeding in brackish waters in the Batticaloa district as a result of the 2004 tsunami or only opportunistically utilizes brackish water as breeding sites, cannot be established because there have been no previous studies of larvae in such water bodies. An. culicifacies are also able to breed in fresh water bodies located less than one km away from Kallady. There are also no reliable data on the anopheline mosquito prevalence in the Batticaloa and other districts of the Eastern province and carrying out such a study was not previously feasible due to two decades of civil war in this part of the country. A limited study that investigated the human biting mosquitoes in Batticaloa during 1993-1994 detected only An. subpictus s.l. and not An. culicifacies s.l. [32].

Global warming consequent to increasing anthropogenic emissions of $\mathrm{CO}_{2}$ will lead to the melting of polar ice and a rise in sea levels. As a consequence, an increasing number of surface water bodies will become more saline in the coastal areas of many countries. These will provide fertile breeding grounds for the more salt -tolerant Anopheline vectors of malaria parasites and this poses a risk of increasing malaria transmission in coastal areas. Such an effect is likely to be compounded by increasing temperatures generally inducing a spread of the malaria vectors into greater latitudes in the temperate zones [33,34]. The ability of An. culicifacies species E to breed in brackish waters poses a particular problem for Sri Lanka as there are already many areas of the country with brackish surface waters e.g. the Jaffna and Puttalam districts in the north and the west of the island, respectively. Increased breeding of anophelines in selected local water bodies may provide the nuclei for initiating epidemics of malaria in Sri Lanka and elsewhere. For exam- ple, the rapid breeding of the relatively inefficient malaria vector Anopheles annularis in newly built irrigations canals in the north-central province of Sri Lanka was suggested to have triggered malaria epidemics towards the end of the last century [35]. The present findings, therefore, establish the need for systematic larval survey along the coastal belt of Sri Lanka to examine the prevalence of malaria vectors breeding in brackish waters.

\section{Conclusions}

The present study reveals, for the first time in Sri Lanka, the ability of the potential malaria vector species $E$ of the Culicifacies complex to breed in brackish waters. This developed ability may pose a threat of malaria transmission in coastal areas of Sri Lanka. Therefore, a systematic larval survey along the coastal belt of the country is warranted to devise an appropriate vector control measure by the Ministry of Health.

\section{Competing interests}

The authors declare that they have no competing interests.

\section{Authors' contributions}

SNS and RR conceived the study and wrote the manuscript. PJJ and SD performed the field collections MV provided logistic support. PJJ, SD, MV and SNS performed the identification and laboratory studies. All authors read and approved the final manuscript.

\section{Acknowledgements}

This work was supported in part by a grant from the National Science Foundation of Sri Lanka (SIDA/BT/2006/03).

\section{Author Details}

'Department of Zoology, Faculty of Science, University of Jaffna, Jaffna, Sri Lanka, ${ }^{2}$ Department of Zoology, Faculty of Science, Eastern University, Chenkaladi, Sri Lanka and 3/nstitute of Medicine, Universiti Brunei Darussalam, Gadong, Brunei Darussalam

Received: 16 November 2009 Accepted: 21 April 2010

Published: 21 April 2010

\section{References}

1. Surendran SN, Ramasamy R: The Anopheles culicifacies and An. subpictus complexes in Sri Lanka and their implications for malaria control in the country. Trop Med Health 2010, 38:1-11.

2. Samarasinghe L: A situation analysis of malaria in Sri Lanka. In Current Status of Malaria Research in Sri Lanka Edited by: Ramasamy R. Kandy: Institute of Fundamental Studies; 1990:1-8.

3. Amerasinghe PH, Amerasinghe FP, Kondradsen F, Fonseka KT, Wirtz RA: Malaria vectors in a traditional dry zone village in Sri Lanka. Am J Trop Med Hyg 1999, 60:421-429.

4. Amerasinghe PH, Amerasinghe FP, Wirtz RA, Indrajith NG, Somapala W, Preira LR, Rathnayake AMC: Malaria transmission by Anopheles subpictus Grassi in a new irrigation project in Sri Lanka. J Med Entomol 1992, 29:577-581.

5. Surendran SN, Abhayawardana TA, de Silva BGDNK, Ramasamy MS, Ramasamy R: Anopheles culicifacies Y chromosome dimorphism indicates the presence of sibling species ( $B$ and $E$ ) with different malaria vector potential in Sri Lanka. Med Vet Entomol 2000, 14:437-440.

6. Surendran SN, Ramasamy MS, De Silva BGDNK, Ramasamy R: Anopheles culicifacies sibling species B and E in Sri Lanka differ in longevity and in their susceptibility to malaria parasite infection and common insecticides. Med Vet Entomol 2006, 20:153-156.

7. Surendran SN, Hawkes NJ, Steven A, Hemingway J, Ramasamy R: Molecular studies of Anopheles culicifacies (Diptera: Culicidae) in Sri 
Lanka: sibling species $B$ and $E$ show sequence identity at multiple loci. Eur J Entomol 2006, 103:233-237.

8. Panicker KN, Geetha BM, Bheema RUS, Wiswam K, Syryanarayana MU: Anopheles subpictus : vector of malaria in costal villages of southeast India. Current Sci 1981, 50:694-695.

9. Rajakaruna RS, Amerasinghe PH, Galapathy GNL, Konradsen F, Briet JT, Alifrangis M: Current status of malaria and antimalarial drug resistance in Sri Lanka. Cey J Sci (Bio Sci) 2008, 37:15-22.

10. Briet OJT, Galapathy GNL, Amerasinghe PH, Amerasinghe HP: Maps of the Sri Lanka malaria situation preceding the tsunami and key aspects to be considered in the emergency phase and beyond. Malar J 2005, 4:8.

11. Christophers SR: The Fauna of British India, including Ceylon and Burma. Diptera 4. Family Culicidae. Tribe Anopheline Taylor \& Francis, London; 1933.

12. Amerasinghe FP: A guide to the identification of the anopheline mosquitoes (Diptera: Culicidae) of Sri Lanka -I Adult females. Ceylon J Sci (Bio Sci) 1990, 21:1-16.

13. Amerasinghe FP: A guide to the identification of the anopheline mosquitoes (Diptera: Culicidae) of Sri Lanka -II Larvae. Ceylon J Sci (Bio Sci) 1992, 22:1-13

14. Suguna SG, Rathinam KG, Rajavel AR, Dhanda V: Morphological and chromosomal descriptions of new species in the Anopheles subpictus complex. Med Vet Entomol 1994, 8:88-94

15. Russell PF, Rao TR: On the ecology of larvae of Anopheles culicifacies Giles, in borrow-pits. Bull Entomol Res 1942, 32:341-361.

16. Sabesan S, Krishnamoorthy K, Jambulingam K, Rajendran G, Kumar PN, Rajagopalan PK: Breeding habitats of Anopheles culicifacies in Rameshwaram Island. Indian J Med Res 1986, 84:44-52

17. Roberts D: Mosquitoes (Diptera: Culicidae) breeding in brackish water Female ovipositional preference or larval survival? J Med Entomol 1996, 33:525-530

18. Carter HF: Further observations on the transmission of malaria by anopheline mosquitoes in Ceylon. Ceylon J Sci 1930, 2:159-176.

19. Amerasinghe FP, Ariyasena TG: A larval survey of surface water breeding mosquitoes during irrigation development in the Mahawali Project, Sri Lanka. J Med Entomol 1990, 22:789-802.

20. Amerasinghe FP, Indrajith NG, Ariyasena TG: Physico-chemical characteristics of mosquito breeding habitats in an irrigation development scheme in Sri Lanka. Ceylon J Sci (Bio Sci) 1995, 2:13-29.

21. Kondradsen $F$, Matsuno $Y$, Amerasinghe FP, Amerasinghe PH, Hoek W van der: Anopheles culicifacies breeding in Sri Lanka and options for control through water managmenet. Acta Trop 1998, 71:131-138.

22. Reuban R, Kalyanasundaram M, Suguna G: Salinity tolerance of sibling species in the taxon Anopheles subpictus Grassi, 1899. Indian J Med Res 1984, 80:67-70

23. Kannathasan S, Antonyrajan A, Srikrishnaraj KA, Karunaratne SHPP, Karunaweera ND, Surendran SN: Studies on prevalence of anopheline species and community perception of malaria in Jaffna district, Sri Lanka. J Vector Borne Dis 2008, 45:231-239.

24. Surendran SN, Ramasamy R: Some characteristics of the larval breeding sites of Anopheles culicifacies species B and E in Sri Lanka. J Vector Borne Dis 2005, 42:39-44.

25. Coluzzi M, Sabatini A: Cytogenetic observations on the salt water species, Anopheles merus and Anopheles melas of the Gambiae complex. Parassitologia 1969, 11:177-187.

26. Sweeney AW: Larval salinity tolerance of the sibling species of Anopheles farauti. J Am Mosa Cont Assoc 1987, 3:589-592.

27. Dusfour I, Harbach RE, Manguin S: Bionomics and systematics of the oriental Anopheles sundaicus complex in relation to malaria transmission and vector control. Am J Trop Med Hyg 2004, 17:518-524.

28. Krishnamoorthy K, Jambulingam P, Natarajan R, Shiriram AN, Das PK, Sehgal $S$ : Altered environment and risk of malaria outbreak in South Andaman, Andaman \& Nicobar islands, India affected by the tsunami disaster. Malar $J$ 2005, 4:32.

29. Kumari P, Joshi PL, Lal S, Shah W: Management of malaria threat follwoing tsunami in Andaman \& Nicobar Islands, India and impact of altered environment created by tsunami on malaria situation of the islands. Acta Trop 2009, 112:204-211.

30. Balaraman K, Sabesan S, Jambulingam P, Gunasekaran K, Doss PB: Risk of outbreaks of vector-borne diseases in the tsunami hit areas of southern India. Lancet Infect Dis 2005, 5:128-129.

31. Briet OJT, Galapathy GNL, Amerasinghe PH, Konradsen F: Malaria in Sri Lanka: one year post-tsunami. Malar J 2006, 5:42.
32. Sujarahini K, Ramasamy MS, Dharmaratnam M: Night human biting mosquitoes during the northeast monsoon in Batticaloa (dry zone) of Sri Lanka. JSC-EUSL 2001, 2:16-25.

33. Githeko AK, Lindsay SW, Confalonieri UE, Patz JA: Climate change and vector-borne diseases: a regional analysis. Bull World Health Organ 2000, 78:1136-1143.

34. Lindsay SW, Birley $\mathrm{MH}$ : Climate change and malaria transmission. Ann Trop Med Parasitol 1996, 90:573-588.

35. Ramasamy R, de Alwis R, Wijesundere A, Ramasamy MS: Malaria transmission at a new irrigation project in Sri Lanka: the emergence of Anopheles annularis as a major vector. Am J Trop Med Hyg 1992, 47:547-553.

doi: $10.1186 / 1475-2875-9-106$

Cite this article as: Jude et al., Anopheles culicifacies breeding in brackish waters in Sri Lanka and implications for malaria control Malaria Journal 2010, 9:106

\section{Submit your next manuscript to BioMed Central} and take full advantage of:

- Convenient online submission

- Thorough peer review

- No space constraints or color figure charges

- Immediate publication on acceptance

- Inclusion in PubMed, CAS, Scopus and Google Scholar

- Research which is freely available for redistribution 